\title{
Alfabetização visual para a produção de objetos educacionais
}

\author{
Anita Grando ${ }^{1}$, Mary Lúcia Pedroso Konrath ${ }^{1}$, Liane Tarouco $^{2}$ \\ ${ }^{1}$ CINTED - Universidade Federal do Rio Grande do Sul (UFRGS) \\ Av Paulo Gama 110, Prédio 12105 - sala 327 - 90490-900 - Porto Alegre - RS - Brazil \\ ${ }^{2}$ Pós-Graduação Informática na Educação - UFRGS \\ \{anita@pgie.ufrgs.br, liane.tarouco@ufrgs.b
}

\begin{abstract}
Resumo. Este artigo descreve alguns princípios para a produção de objetos educacionais ergonômicos, os quais possibilitam a maximização da aprendizagem com redução da sobrecarga cognitiva.
\end{abstract}

Palavras-chave: objetos educacionais, projeto gráfico, carga cognitiva

Abstract. This article describes some principles for the design of learning objects, considering human factor principles to maximize learning with minimal cognitive load.

Key words: learning objects, web design, cognitive load

\section{Alfabetização visual para a produção de objetos educacionais}

\section{Produzindo objetos educacionais ergonômicos}

As futuras gerações trabalharão cada vez mais com tecnologias de aprendizagem interativas pois as rápidas transformações nos meios e nos modos de produção vão requerer um constante aprendizado por parte da força de trabalho. $\mathrm{O}$ retorno aos bancos escolares nem sempre será possível ou factível mas o mergulho em ambientes de aprendizagem apoiados por redes e computadores, que viabilizaram cenários de ensinoaprendizagem virtuais, com interação mediada por computador e que poderão estar disponíveis em qualquer momento e a partir de qualquer lugar, poderá assegurar a possibilidade de educação continuada.

Com a intensificação do uso da web como apoio na aprendizagem há necessidade de uma investigação sobre como os estudantes processam e compreendem a informação apresentada em sites WWW. A tecnologia atualmente disponível enseja diversificados modos de organização da informação com diferentes implicações cognitivas associadas às diferentes opções (Pour 2002). A produção de material educacional baseado em WWW demanda considerável esforço, especialmente quando envolve multimídia e portanto é desejável que sua produção possa ser conseguida sem 
desperdício de esforço e que atenda a quesitos de qualidade. Neste sentido, práticas derivadas da engenharia de software começaram a ser aplicadas no projeto deste material educacional a ser usado no contexto das redes e computadores. Orientação a objetos, linguagens de autoria de alto nível, ambientes de desenvolvimento são algumas das alternativas sendo atualmente usadas. O material começa a ser estruturado em objetos educacionais, que agregados compõem objetos mais complexos e assim sucessivamente (Wiley 2003). O projeto de objetos educacionais com vistas à sua reusabilidade é um dos principais resultados da atividade de grupos de trabalhos como o IEEE (1484.12.1-2002 Standard for Learning Object Metadata) e ISSO (SC 36 Information Technology for Learning, Education and Training).

Em decorrência, utilizando sistemas de ensino-aprendizagem altamente interativos é possível oportunizar um ambiente ativo e aberto de aprendizagem onde os estudantes trabalham visando desenvolver seus planos individuais, com base em suas habilidades, conhecimento e interesses. Neste sentido a organização do material educacional em pequenos segmentos que serão agregados em função das necessidades de aprendizagem dos estudantes é altamente desejável.

O projeto destes objetos educacionais deve levar em conta tanto aspectos inerentes a teorias de

aprendizagem como combinar o conhecimento de outras áreas como ergonomia, engenharia de sistemas e levar ainda em conta as potencialidades e limitações da tecnologia envolvida.

O propósito deste trabalho é relatar o resultado de algumas investigações concernentes ao impacto cognitivo de diferentes estratégias de projeto de objetos educacionais especialmente tendo em vista a sua apresentação visual. Neste sentido, foram compiladas recomendações derivadas da área de "web design" mas ajustadas ao cenário educacional.

\section{Efeitos cognitivos do design de páginas}

$\mathrm{O}$ advento do ensino baseado na web, que conta com modelos hipertextuais de interação e design, enfatiza a necessidade de uma compreensão clara de como os aprendizes processam e codificam as informações apresentadas em websites com propósitos educacionais.

O caráter exclusivo do design de páginas web, imposto pelos obstáculos da tecnologia que limita a interatividade dos estudantes, mas que mesmo assim suporta explorações divergentes, exige uma consideração mais profunda sobre como os aprendizes interagem com os vários fatores do design de websites.

\section{Sobrecarga cognitiva}

A carga cognitiva refere-se às demandas colocadas na memória de trabalho do aprendiz durante a instrução. No caso da instrução baseada por computador ou da instrução baseada na web, o termo cobre tanto o processo mental necessário para 
acessar e interpretar as telas, ícones e objetos, como o processo cognitivo dedicado para processar o real conteúdo da instrução.

O objetivo de um bom design de página para uso educacional é, naturalmente, reduzir a quantidade de processamento direcionado à interação com o sistema e maximizando o processamento do conhecimento que está sendo ensinado.

A carga cognitiva é um fator sempre presente no design de telas e interfaces de computador porque cada um dos elementos ou dos objetos da tela deve ser interpretado pelo usuário e conseqüentemente ocupa alguma energia mental do usuário. Um design de tela complexo ou nãoconvencional que usa diferentes fontes, objetos, ferramentas da navegação, e padrões de layout terá geralmente uma carga cognitiva processual ou funcional elevada porque cada componente necessitará ser percebido e interpretado pelo aprendiz. Uma tela que use convenções padrão no texto, gráficos, navegação e layout será mais facilmente interpretada e conseqüentemente terá uma carga cognitiva muito mais baixa.

É difícil ensinar estudantes a dedicar menos esforço cognitivo para atividades relacionadas ao processamento do aspecto das páginas, mas é relativamente bem mais simples projetar websites que exibam a informação de uma maneira consistente e transparente. O termo transparência significa que as funções relacionadas às opções do sistema são óbvias ao usuário e conseqüentemente envolvem mínimo esforço cognitivo. Isto pode ser conseguido com o uso de padrões simbólicos amplamente aceitos para elementos de tela e através de rótulos ou ícones explícitos associados a escolhas ou tarefas. $\mathrm{O}$ aspecto chave da transparência é que o usuário não deve ter que pensar sobre suas ações, mas simplesmente responder de uma maneira intuitiva.

\subsection{Minimizando a carga cognitiva}

Projetistas de ambientes de aprendizagem utilizam multimídia e interatividade como forma de conseguir uma aprendizagem mais eficaz . Todavia, em alguns ambientes, estes fatores podem resultar em um efeito de distração e causar um impacto negativo no processo de aprendizagem resultando num aumento da carga cognitiva, ou seja, da quantidade de recursos cognitivos alocados a uma tarefa específica, conforme definido em (Ining 2003) que relata medições efetuadas com o uso de biosensores (monitoradores de movimento de olho que verificam fixação do olhar, piscadas, dilatação da pupila etc..., medidas de pressão sangüínea, temperatura e pressão da mão no mouse), para avaliar este impacto. Experimentos referidos no trabalho de Iding (Crosby 2001) mostraram que dados fisiológicos podem ser usados para inferir estados cognitivos, incluindo a carga cognitiva. Um dos equipamentos desenvolvidos para apoiar esta pesquisa foi um mouse capaz de medir a pressão exercida pelo usuário sobre o mesmo, para usar esta informação como um dos indicadores de carga cognitiva.

Experimentos puderam então ser organizados para avaliar a carga cognitiva de diversificadas estratégias de web design para uso educacional sendo derivadas uma série de recomendações.

\subsection{Recomendações}


Mas mesmo na inexistência de dispositivos sensores tais como os usados por Iding, é possível avaliar embora parcialmente, o esforço de inspeção pelo aluno do material educacional a ele apresentado. Experimentos combinando a observação dos usuários enquanto utilizavam material educacional on-line, combinado com o tempo decorrido entre a carga de uma etapa e a subsequente também foram usados para derivar conclusões sobre se cada parte do material de aprendizagem estava demandando um esforço mais intenso e resultaram em alterações na forma e na quantidade de informação apresentada (Lindermann 1982). A partir desta experiência diversas recomendações para o projeto da apresentação da informação foram derivados com vistas a reduzir a carga cognitiva do estudante envolvido na utilização do material (Lindermann 1983), tais como:

- $\quad$ Simplicidade do texto, em quantidade e qualidade. Cada segmento de informação deve poder ser exibido no vídeo sem requerer o uso de barra de rolamento. As sentenças devem ser curtas, preferencialmente em ordem direta evitandose o uso de referências a informações que já apareceram ou que se encontram mais adiante no texto. Deve ser evitado o uso de abreviações e jargão excessivo, especialmente quando a população alvo é principiante. Siglas devem ser usadas com cautela.

- $\quad$ Formatação confortável. A disposição do texto e das imagens devem buscar uma harmônica combinação. Imagens devem ser colocadas bem próximas de onde são referenciadas. No caso de imagens grandes ou detalhadas, pode-se colocar uma imagem reduzida e se o usuário desejar ver em maior detalhamento, clica e recebe a forma ampliada da mesma. Cabeçalhos e pequenos textos a destacar podem ser centralizados mas o restante do texto deve ser alinhado à esquerda pois, como o modo ocidental de leitura percorre as linhas da esquerda para a direita, esta forma de alinhamento reduz a carga cognitiva derivada do esforço de procurar o início da próxima linha a ser lida. As informações mais importantes devem estar localizadas no canto superior esquerdo. No que tange à forma, deve ser evitado o uso excessivo de elementos de destaque (negrito, tamanho diferenciado, cores, texto piscante etc...) embora seu uso comedido seja apropriado para destacar idéias chave. Letras não serifadas como a fonte Helvetica tem melhor legibilidade e seu uso é sugerido para uso em páginas com material educacional (Burmark 2002). No caso de links é recomendável que se use cor para realçar ao invés de usar sublinhado.

- $\quad$ Cores. A cor é uma importante propriedade estética em uma página na web. Devido a suas qualidades atrativas podemos usar a cor para identificar os elementos que devem atrair a atenção do usuário. Todavia, cor é uma propriedade muito subjetiva e o que é agradável para alguém pode ser desagradável para outro. A interpretação de cor pode variar culturalmente, e até mesmo em uma única cultura as associações individuais podem diferir. Quando usada indiscriminadamente, a cor pode ter um efeito negativo ou de distração causando fadiga visual (cansaço visual causado pelo número excessivo de elementos visuais ou cores em uma única página) resultando em elemento que distrai a atenção do usuário e causa a perda de foco na atividade principal. Quando a página tiver um fundo colorido, deve-se selecionas as cores do texto de modo a obter o contraste mais forte entre o texto e o fundo. Isso aumenta a 
visibilidade e a legibilidade do texto. Cores complementares (cores que se encontram opostas no círculo cromático, como por exemplo o vermelho e verde) devem ser usadas para fundo e texto. Mas é importante considerar que aproximadamente $8 \%$ dos homens e $0,5 \%$ das mulheres têm deficiência em visualizar cores, sendo que o mais frequiente é a falta de habilidade para distinguir o vermelho, o amarelo e o verde. Para evitar problemas com usuários com visão deficiente de cores, as cores como vermelho e verde devem ter brilho suficientemente diferentes. Muitas outras recomendações pertinentes sobre o uso de cor podem ser encontradas em Guia de Estilos para Serviços de Informação em Ciência e Tecnologia (Parizotto1997).

- Segmentação. O projeto da disposição das informações em um monitor de vídeo exige uma certa estética e freqüentemente se incorre em um erro que é o de tentar colocar numa mesma página uma grande quantidade de informações, mesmo às custas de reduzir o tamanho dos caracteres ou de "espremer" o texto ocupando toda a área disponível. Isto torna difícil e monótona a leitura. Espaços em branco ajudam a destacar o texto. Adicionalmente é preciso atentar para a carga cognitiva associada ao conteúdo a ser apresentado e buscar estratégias para reduzi-la. A carga cognitiva referese ao trabalho total imposto à memória de trabalho num dado instante. Um dos principais fatores a contribuir para a carga de cognitiva é a quantidade de elementos para os quais temos que atentar naquele dado instante pois o cérebro tem uma memória de trabalho com capacidade limitada, sendo que essa é a responsável pela entrada e armazenamento sensorial das informações. Alguns estudos empíricos os cientistas indicam que é recomendável organizar a informação em grupamentos (7 +- 2 grupamentos são recomendados). Cooper refere que quando a carga cognitiva extrínseca (derivada da forma do material a ser usado na aprendizagem) é elevada, e a carga cognitiva intrínseca (derivada da natureza do que deve ser aprendido) também, pode ser haver falha na aprendizagem. Uma vez que a carga cognitiva intrínseca (inerente a um conteúdo difícil) não pode ser alterada, é preciso investir na redução da carga cognitiva extrínseca, modificando o material educacional com vistas à reduzir a carga cognitiva extrínseca (Cooper 1997). Ele também sugere que quando a carga cognitiva intrínseca é muita elevada (conteúdo muito difícil) o uso de gráficos, imagens contribui para a redução desta carga cognitiva.

- Uso de imagens e gráficos. Numa sociedade onde interesses poderosos empregam dados visuais para persuadir (o que Alvin Toffler chamou de "info-tatics") os educadores devem ser capazes de empregar imagens e multimídia nos ambientes de ensino-aprendizagem que constroem. Considerando que a geração atual quase não lê e que os jovens aprendem mais da metade do que sabem a partir de informação visual, percebe-se a importância de usar na comunicação elementos de imagem, animação e som. Com multimídia educativa pretende-se maior efetividade na aprendizagem motivando os alunos a devotar mais tempo e energia à atividade de aprendizagem. O projeto visual podem envolver elementos com maior ou menor grau de realismo, tal como ilustra a figura 1. Há estudos apontando que, sob certas circunstâncias, realismo pode interferir no processo de comunicação e aprendizagem e distrair, tal como mostrado na figura 2.

Figura 1: Grau de realismo dos elementos gráficos 
Figura 2: Grau de ralismo e aprendizagem

\section{Efeitos Cognitivos do Design de Páginas Web}

A navegação hipertextual produz um tipo diferente de estratégia ou intenção instrucional. Este tipo de fenômeno pode ser denominado estratégia de navegação porque reflete as estratégias intencionais empregadas por indivíduos na navegação ou busca na Web. É descrito por características como "folhear" mais do que por leitura do texto, pela busca e pela seleção visual rápida dos botões ou links, e por uma impaciência para passar para a próxima página. Basta gastar uma hora ou duas observando estudantes interagindo com a web para reconhecer os efeitos.

A tecnologia do hipertexto e da web é baseada neste tipo de interação. Isto não significa dizer

que a interação deste tipo é ruim ou que não produz aprendizagem, particularmente quando o pensamento criativo e divergente é desejável. A dificuldade surge quando esta forma de interatividade é aplicada a ambientes instrucionais ou conteúdo no qual uma interação mais profunda com o conteúdo é desejada ou exigida. O usuário que simplesmente passa pelos conteúdos de uma página web pode identificar termos e conceitos gerais, mas a base conceitual e os aspectos elaborados do material serão perdidos.

Um dos efeitos da navegação hipertextual e que causa desorientação do usuário é atribuído à grande quantidade de informação apresentada de forma desestruturada, o que é característica da maioria dos ambientes hipertextuais e o nível elevado de controle pelo usuário que o sistema permite.

Estas duas características podem trabalhar junto para aumentar a quantidade de carga cognitiva imposta ao usuário, tendo por resultado o que pode ser chamado de "hiperchaos".

Aqueles websites que fornecem um rico ambiente hipermídia correm o risco de sobrecarregar o usuário novato com escolhas de navegação e informação que podem facilmente impressionar ou confundir o estudante.

Wayfinding (orientação ou encontrar o caminho) é um termo que emergiu da pesquisa sobre como os indivíduos atravessam um ambiente hipertextual. Wayfinding significa a habilidade de mover-se através de um ambiente físico ou (em termos de hipertexto) de informação sem ficar perdido. Wayfinding efetivo é dependente não somente de saber aonde alguém está indo, mas também em saber onde alguém esteve, que sugere que os designers devem não somente fornecer ferramentas de navegação consistentes e intuitivas, mas também definir claramente mapas do espaço da informação que constituem qualquer website instrucional.

Wayfinding é fortemente dependente das habilidades cognitivas do aprendiz, particularmente aquelas que se relacionam à orientação espacial. A habilidade de 
visualização espacial foi estudada para determinar que o grau de habilidade de manipular mentalmente a informação espacial está relacionada à habilidade de navegar através de um espaço de informação. Foi constatado que, aumentando a aparência da interface através de sugestões gráficas ou estruturas de mapas, todos os usuários podem ser ajudados, mas particularmente aqueles com habilidades espaciais mais baixas.

Outros aspectos a serem considerados no design de página web é concernente à interatividade. O conceito "interatividade" é de fundamental importância para o estudo da comunicação mediada por computador, da educação à distância, da engenharia de software e de todas as áreas que lidam com a interação homem-máquina e homemhomem via computador. Nos primórdios do uso da multimídia interativa, era pressuposto, tanto no entendimento leigo quanto em muitos círculos técnico-científicos, que havendo ícones clicáveis e textos segmentados em partes e ligados por palavrasâncora ou imagens (hyperlinks) o resultado constituia exemplo definitivo de interatividade. Mas a tecnologia hoje disponível permite a implementação de ambientes de intensa interatividade, longe da pré-determinação estrita, onde os interagentes podem interagir mais criativamente, onde a interatividade possa ter lugar, sem que o estudante fique preso à relação ação-reação ou tenha que adequar-se a inputs determinados que geram sempre e necessariamente os mesmos outputs. A combinação de conceitos da Inteligência Artificial tem produzido, por exemplo, os chat robots que são capazes de emular razoavelmente o comportamento de um especialista humano em determinado campo do conhecimento e responder a questões apresentadas em linguagem natural. $\mathrm{O}$ uso de realidade virtual permite a construção de laboratórios virtuais onde os estudantes podem agir sobre dispositivos virtuais, através de avatares que os representam. Através de modelos de software, tais como simulação com vizualização gráfica em tempo real, um estudante pode ser imerso em um ambiente sintético construtivista capaz de oferecer muitas destas condições. O estudante atua e colabora não como ele próprio mas via um avatar, um pessoa que o representa no mundo virtual e que pode realizar experimentos e se "mover". Esta abordagem aperfeiçoa a habilidade dos estudantes para aplicar conhecimento abstrato situando a educação em contexto virtual similar ao ambiente em que as habilidades dos estudantes possam ser usadas. Estas formas de interatividade foram testadas no âmbito do projeto ARCA - que buscou o desenvolvimento de um ambiente de ensino aprendizagem que, apoiado pela Internet, pudesse atuar como instrumento no auxílio à uma prática pedagógica diferenciada. Diversos aspectos foram analisados para a construção e operação deste ambiente com vistas à sua otimização, tanto no que tange a aspectos de desempenho na rede e nos sistemas computacionais envolvidos como no que tange às suas características de adequado interfaceamento e condições para suporte à construção do conhecimento (TAROUCO 2001).

\section{Conclusões}

Como decorrência da argumentação construída neste trabalho, apontando a relevância da consideração a aspectos ergonômicos no projeto de objetos educacionais apoiados em redes e computadores, caberia, a título de finalização, destacar a necessidade de proporcionar aos docentes envolvidos na construção deste tipo de material educacional uma alfabetização visual agregada à alfabetização digital que tem sido objeto de tanto esforço de capacitação nos últimos anos. Em se desconsiderando a importância e necessidade desta capacitação em detrimento da pura formação para o uso da tecnologia corre-se o risco de colocar esforços na produção de material educacional 
que por não atentar para estes aspectos resulte em carga cognitiva extrínseca mais elevada prejudicando o processo de aprendizagem que seriam supostos catalizar.

\section{Referências}

BURMARK, Lynell . Visual Literacy: Learn to See, See to Learn. Association for Supervision and Curriculum Development (ASCD). 2002.

COOPER, Graham. Research into Cognitive Load Theory and Instructional Design at UNSW. http://www.arts.unsw.edu.au/education/CLT_NET_Aug_97.HTML Acesso em junho 2003.

CROSBY, M., Auernheimer, B., Aschwanden, C., and Ikehara, C., 2001. Physiological data feedback for application in distance education. Workshop on perceptive user interfaces, Florida.

IDING, Marie et alli. Cognitive load and adaptative instructional designs for computer-based learning. In: IADIS INTERNATIONAL E-SOCIETY 2003 CONFERENCE, 2003, Lisboa, Portugal. e-Society 2003. p 1021-1022.

DOWNES, Stephen. Learning Objects: Resources For Distance Education Worldwide. In: IRRODL: International Review of Research in Open and Distance Learning. Athabasca University: july, 2001.

GRANDO, Anita Raquel Cestari da Silva. Tarouco, Liane Margarida Rockenbach. Animações multimídia para apoiar o processo de construção do conhecimento : In: Salão de Iniciação Cientfica (14. : 2002 : Porto Alegre) Livro de resumos. Porto Alegre : UFRGS/PROPESQ, 2002. p. 841

IDING, M., 2000. Is seeing believing? Features of effective multimedia for learning science. International Journal of Instructional Media, 27(4), 403-415.

ISO Information Processing Systems -- Open Systems Interconnection -- The Directory: Overview of Concepts, Models and Service. ISO/IEC JTC 1/SC21; International Standard 9594-1, 1988.

IEEE. Learning Technology Standards Committee (LTSC). Draft Standard for Learning Object Metadata (IEEE P1484.12.1/D6.4). Disponível em: http://ltsc.ieee.org/doc/wg12/LOM_WD6_4.pdf

LINDERMANN. H.V, Tarouco, Liane; Klein, S.P., Amaral, K.E.F. do. \&. L'informatique pour une communaute non-informatisee. In: Congres de la Societe D'Ergonomie de Langue Française, 18. 13 a 15, Oct., 1982, Paris.

LINDERMANN, Helena. Os sistemas do futuro e seus aspectos ergonômicos. In: Boletim Dc. Porto Alegre vol. 4, n. 1 (jan. 1983), p. 14-18

PARIZOTTO, Rosamélia. Guia de estilo para informação em Ciência e Tecnologia via web. UFSC. 1997. Disponível em http://www.labiutil.inf.ufsc.br/estilo/Guia.htm (consultado em Junho 2003). Pour, Mehdi. Web-based Instructional Learning. IRM Press. London. 2002.

SABANI, Claudia. Informática, ergonomia e doenças profissionais. In: Congresso Nacional de Informática (22. : 18-22 set. 1989 : São Paulo). Anais. São Paulo : Sucesu, 1989. p. 9-13 
TAROUCO, Liane; GELLER, Marlise; MEIRELLES, Luiz. Cooperative Virtual Reality Environment for Learning - ARCA. In: PROJECTS EVALUATION WORKSHOP - PROTEM-CC INFORMÁTICA

NA EDUCAÇÃO, 2001, Rio de Janeiro. PROTEM-CC Informática na Educação. 2001. p. 142-160. WILEY, David A. (Ed.). The Instrucional Use of Learning Objects: Online Version. Disponível em: http://reusability.org/read/. Acesso em 20 jun. 2003. 